Religare, ISSN: 19826605, v.14, n.1, agosto de 2017, p. 60-89.

\title{
Os cientistas franceses e o estudo do paranormal: controvérsias e avanços
}

\author{
The french scientists and the study of paranormal: \\ controversies and advances
}

Marion Aubrée 1

Genaro Camboim L. A. Lula

\section{Resumo}

Este texto pretende mostrar abordagens de alguns cientistas sociais francófonos sobre a discussão de um tema específico, isto é, a questão de saberes e práticas que lidam com fenômenos insólitos, muitas vezes conhecidos também por "paranormais". Falaremos tanto de como as práticas e discursos sobre os estados alterados de consciência em práticas de transe, mediunidade, vidência vem sendo discutidos em alguns autores nas últimas décadas tentando distingui-los em suas especificidades quanto em suas aproximações. Não procuramos exaurir o tema em um quadro de análise comparativa entre os autores, não obstante, também não nos isentamos em mostrar algumas diferenças metodológicas e filiações teóricas a que estão sujeitos. Se os fenômenos paranormais e os Estados Modificados de Consciência - EMC foram, desde tempos imemoriais, fonte de questionamentos para outros saberes de outras as épocas e outras as disciplinas é, na modernidade secularizante, alvo de suspeitas e rejeição. Somente nas últimas décadas, o esforço de alguns cientistas sociais, historiadores e psicólogos em estudar essa própria rejeição e de começar a construir abordagens que consigam superar as suspeitas sobre as práticas, os discursos e as técnicas ligadas a estes fenômenos. Este artigo aponta exatamente para o esforço de alguns autores que vem nas últimas décadas publicando resultados de pesquisas e elaborando categorias como a de ortoprática e paraciência que visam colocar o mundo dos fenômenos paranormais e dos EMC em modelos não-patologizantes e excludentes, porém baseados em uma contrutivismo.

Palavras-chave: Paraciências, controvérsias científicas, EMC, ufologia, vidência, Construtivismo

\footnotetext{
${ }^{1}$ Doutora em Antropologia. Docente aposentada (CRBC/CéSor - EHESS Paris)

2 Doutorando em Antropologia PPGA/UFPE e prof. Adjunto I - Universidade do estado do Rio Grande do Norte - UERN
} 


\section{Abstract}

This text intends to show approaches of some Francophone social scientists on the discussion of a specific theme, that is, the knowledge and practices that deal with unusual phenomena, often also known as "paranormal". We will adress how the practices and discourses about altered states of consciousness in trance, mediumship, and clairvoyance have been discussed by some authors in the last decades and trying to distinguish them in their specificities and in their approximations. We do not attempt to exhaust the theme in a framework of comparative analysis among the authors, nevertheless, we are not exempt from showing some methodological differences and the theoretical affiliations to which they are subject. If the paranormal phenomena and the Altered States of Consciousness - ASC have been, from time immemorial, source of questioning for other types of knowledge of different times and disciplines, is, in the secular modernity, the object of suspicion and rejection. Only in recent decades has the effort of some social scientists, historians, and psychologists to study this rejection itself and to begin to build approaches that can overcome suspicions about the practices, discourses, and techniques associated with these phenomena. This article points precisely to the efforts of some authors who have been publishing research results in the last decades and elaborating categories such as orthopractics and parascience, which aim to put the world of paranormal phenomena and ASCs into non-pathological and exclusive models, but constructivist ones.

Keywords: Parascience, scientific controversies, ASC, ufology, clairvoyance, Constructivism

\section{Introdução}

Não é novidade a influência sobre a antropologia e a sociologia da religião produzida no Brasil da literatura elaborada pelas ciências sociais em língua francesa. Neste quesito, consideramos desnecessário retomar a presença de conceitos desenvolvidos por autores francófonos já considerados clássicos na formação da obra de cientistas sociais brasileiros. Nosso objetivo neste texto é bem mais modesto e consiste em apresentar ao leitor, as démarches (abordagens) de alguns cientistas sociais francófonos na discussão de um tema específico, isto 
Religare, ISSN: 19826605, v.14, n.1, agosto de 2017, p. 60-89.

é, a questão de saberes e práticas que lidam com fenômenos insólitos, muitas vezes conhecidos também por "paranormais". Falaremos tanto de como as práticas e discursos sobre os estados alterados de consciência em práticas de transe, mediunidade, vidência vem sendo discutidos em alguns autores nas últimas décadas tentando distingui-los em suas especificidades quanto em suas aproximações. O nosso objetivo não é, contudo, construir ao final desse percurso uma teoria ou método para a abordagem e interpretação destes saberes e práticas de dissociação psíquica e muito menos nos envolvermos nas discussões sobre a veracidade e a factualidade dos fenômenos. Não obstante, o nosso interesse se pauta muito mais em uma apresentação de iniciativas contemporâneas envolvidas, algumas vezes, em explícitas divergências epistemológicas entre si.

\section{Uma história do conhecimento sobre os EMC}

Os Estados Modificados de Conciência (EMC) foram, desde tempos imemoriais, fonte de questionamentos para sábios e cientistas. Na Antiguidade grega, os ditos estados "irracionais" eram enfocados como uma forma de relação com o sobrenatural e Platão distinguia quatro tipos do que considerava como uma "loucura divina": a profética ligada a Apolo, a ritual relacionada com Dionisio; a poética inspirada pelas Musas et a erótica provocada por Afródita e Eros $^{3}$. Na obra mencionada, o grande helenista britânico analisa as diversas fontes que nos informam sobre a percepção que os gregos antigos tinham desses estados "fora da consciência". Eles os enfocavam, na maior parte das vezes, como várias formas de desordem mental provocada por forças sobrenaturais. Assim, segundo E.R. Dodds, existia, já na época, uma forte distinção entre o que ele chama de "mediunidade apolínia", profetismo extático e individual orientado ao desvelamento do futuro ou de um presente oculto e a "experiencia dionisíaca",

\footnotetext{
${ }^{3}$ Apud E.R. Dodds : Les grecs et l'irrationnel, ed. Flammarion, Paris, 1977, p. 71.
} 
Religare, ISSN: 19826605, v.14, n.1, agosto de 2017, p. 60-89.

unicamente coletiva e contagiosa, procurada em vista da obtenção de um certo bem-estar e na qual a mântica não exerce nenhum papel ${ }^{4}$.

$\mathrm{O}$ interesse para esses EMC não se retraiu no curso do tempo, como o mostram os trabalhos históricos de A. Faivre ${ }^{5}$ e J. Servier ${ }^{6}$, porém a dinâmica racionalizante que ganhou toda Europa ocidental e, muito particularmente, a França a partir do século XVII, contribuiu na redução desses interesses "irracionais". Não obstante, a atração do mistério perdurou, na França como em outros lugares, e o período revolucionário que afetou estruturas sociais envelhecidas, alimentou as tentativas de dar explicações para os múltiplos enigmas e novos fenômenos que perturbavam a marcha triunfante da ciência positivista ocidental ${ }^{7}$. Ao longo do século XIX surgiram correntes de pensamento assim como crenças novas cujo objetivo era interpretar, cada um à sua maneira, as manifestações "estranhas" que escapavam da compreensão ordinária e racional $^{8}$. No princípio do século XX, instituições históricas como o Instituto de Metapsíquica Internacional - IMI, criado em 1919 pelo mecenas Jean Meyer e pelo Prêmio Nobel Charles Richet para perscrutar o suprassensível, procurava, com algumas dificuldades e com o olhar crítico da academia, fazer uma síntese entre reflexões metafísicas oriundas de fontes diversas (espiritismo, teosofia, maçonaria) e os últimos desdobramentos da ciência.

Assim podemos dizer que somente a partir da segunda metade do século XX, o mundo acadêmico francês começou, graças aos historiadores das religiões, a dar conta timidamente dos numerosos estudos feitos durante os dois séculos anteriores sobre o conjunto das correntes esotéricas. Esse reconhecimento se concretizou através da criação no ano de 1964 de uma “Cátedra de História do

\footnotetext{
4 Ibid. pp. 73-75.

${ }^{5}$ A. Faivre : Accès de l'ésotérisme occidental, ed. Gallimard (2 vol.), Paris, 1996. (Acesso ao esoterismo occidental).

${ }^{6}$ J. Servier : Dictionnaire critique de l'ésotérisme, éd. PUF, Paris, 1998. (Dicionario crítico do esoterismo).

7 Sobre esse assunto cf. M. Aubrée et F. Laplantine, La Table, le Livre et les Esprits, éd. JC Lattès, Paris, 1990. Publicado em português em 2009 pela EDUFAL.

8 Para o análise dessa dinámica na França, ver Bertrand Méheust : Somnambulisme et médiumnité (2 vol.), Institut Synthélabo para o progresso do conhecimento, Le Plessis-Robinson, 1999.
} 
esoterismo cristão" na seção "Ciências Religiosas" da Ecole Pratique des Hautes Etudes - EPHE, na Sorbonne de Paris. O primeiro titular foi François Secret, até 1979, momento em que foi substituído por Antoine Faivre que modificou a apelação por "História das correntes esotéricas e místicas na Europa moderna e contemporânea" $^{\prime 9}$. De um ponto de vista metodológico essa mudança de apelação tinha por interesse ampliar o campo da pesquisa muito além do cristianismo. Após essa institucionalização de uma disciplina até então negligenciada a nível acadêmico, outras cátedras do mesmo tipo foram criadas em outros países europeus: em 1999 na Universidade de Amsterdam e, em 2002 e 2006, nas universidades britânicas de Lampeter e d'Exeter ${ }^{10}$. Além desses trabalhos de análise histórica vários pesquisadores em ciências exatas, geralmente matemáticos, se interessaram cedo por esses fenômenos como foi o caso, entre outros, de Henri Broch ${ }^{11}$ cuja cátedra sobre o paranormal tinha sido fundada na Universidade de Nice-Sofia Antipolis já no ano de 1953. Na Inglaterra, foi a sucessão/herança de Arthur Koestler, ele próprio interessado pelos fenômenos paranormais, que permitiu a criação em 1985 de uma cátedra de parapsicologia na Universidade de Edimburgo.

Paralelamente a esses trabalhos acadêmicos floresceu na Europa, nos anos 1960, um conjunto de obras mais ou menos inspiradas pelo movimento literário do « realismo fantástico» muito vivo naquela época na América Latina ${ }^{12}$. Várias dessas obras, nem um pouco acadêmicas, se constituíram em vetores do interesse de toda uma geração para sacudir o jugo racionalizante através da descoberta de experiências, mais ou menos fantásticas, vividas por alguns ocidentais a partir de tradições culturais outras ${ }^{13}$. Enquanto os trabalhos de campo dos sócio

\footnotetext{
${ }^{9} \mathrm{O}$ atual titular dessa cátedra é o Pr. J. P. Brach.

10 Sobre esse particular ver o artigo de Faivre : «Une spécialité nouvelle: "Histoire des courants ésotériques occidentaux", ANNUAIRE de l'EPHE, tome 113, Paris, 2004-2006, pp. 27-44.

11 Cf. desse autor Le paranormal, ses documents, ses hommes, ses méthodes, éd. du Seuil, Paris, 1989.

12 Representam esse movimento literario, entre outros, os Mexicanos M. A. Asturias et Juan Rulfo, o Cubano A. Carpentier, os Argentinos J. L. Borges et Bioy Casares ou o Colombiano G. García Marquez. 13 Entre outros, C.H. Hoskin (alias Lobsang Rampa) : Le troisième œil (1958), J. Bergier et L. Pauwels : Le matin des magiciens, éd. Gallimard, Paris, 1960 ou Carlos Castañeda (1968). Todos foram bestsellers traduzidos em várias linguas.
} 
Religare, ISSN: 19826605, v.14, n.1, agosto de 2017, p. 60-89.

antropólogos realizados em países “exóticos" entre os anos 1940 e 1960 는 tinham ficado relativamente confidenciais, essa literatura plasmada pela imaginação levantou entre um amplo público um entusiasmo novo para práticas estrangeiras e fomentou as bases da atual dinâmica do vasto movimento New Age.

Por outra parte, enquanto na Itália, a dimensão "mágica" que tinha se conservado em algumas regiões afastadas tinha sido objeto, desde os anos 1940, das análises do etnólogo Ernesto de $\mathrm{Martino}^{15}$, na França, foi somente a partir dos anos 70 que os pesquisadores de várias disciplinas em ciências sociais começaram a publicar estudos ligados a um conjunto de fenômenos sem explicações imediatas ${ }^{16}$.

\section{A questão da rejeição da academia às expressões “irracionais"}

Por outro lado, à semelhança dos italianos, alguns etnólogos franceses começaram a aplicar os métodos utilizados nos campos exóticos ao estudo de fatos etnográficos próprios do território nacional ${ }^{17}$. Assim começaram a aparecer nos anos 1970/80 vários estudos sobre fenômenos até então considerados como de pouco interesse científico. Depois da análise sobre bruxaria feita por J. FavretSaada, a ufologia, a mediunidade e a vidência foram, também, objetos de várias análises pela sócio-antropologia e pelas ciências psíquicas, provocando numerosas críticas, algumas bem duras, nos meios acadêmicos ${ }^{18}$.

\footnotetext{
${ }^{14}$ Cf., entre outros, M. Leiris : La Possession et ses aspects théâtraux chez les Éthiopiens de Gondar (1958) ; A. Métraux : Religions et magies indiennes d'Amérique du Sud, (1967) ; R. Bastide : Le rêve, la transe et la folie, (1972).

${ }^{15}$ Cf. desse autor: Il monde magico, prolegomeni a una storia del magismo, éd. Einaudi, Roma, 1948. Traduzido ao francês por M. Baudoux, postfacio de S. Mancini em 1971 ; última edição francesa: Le monde magique, éd. Synthélabo,1999.

16 Ver, por exemplo : M. Mélieux e J. Rossignol (dir.) : Corps à prodiges, éd. Tchou, Paris, 1977.

${ }_{17} \mathrm{Cf}$., entre outros, o livro de J. Favret-Saada : Les mots, la mort, les sorts - La sorcellerie dans le Bocage, éd. Gallimard, Paris, 1977.

18 Ver, em particular, o artigo de G. Charuty : "Le retour des métapsychistes", L'Homme, n 158-159, avril/sept. 2001, pp. 353-364 assim como a resposta de S. Mancini e B. Méheust : "La réponse des métapsychistes" L'Homme, $\mathrm{n}^{\circ}$ 161, 2001, pp. 225-238.. Nos Estados Unidos onde foram feitos cêdo estudos acadêmicos sobre as "percepções extrasensoriais" (Rhine, 1934) aqueles trabalhos foram, alí também, objeto de fortes críticas vindas das ciências "duras", cf. em particular o matemático N. J. Levitt, Prometheus bedeviled, Science and the contradictions of comtemporary culture, Rutgers Univ. Press, New Brunswick, 1999.
} 
Religare, ISSN: 19826605, v.14, n.1, agosto de 2017, p. 60-89.

Porém, após a dinâmica lançada pelos matemáticos e historiadores, os primeiros trabalhos em ciências sociais que provocaram uma brecha no duro casco da racionalidade acadêmica o fizeram a partir de um feixe de disciplinas onde se mesclaram filosofia, historia, socio-antropologia, ciências psíquicas e ciências da natureza. A atitude comum aos pesquisadores que se interessaram por ditos fenômenos foi a de salientar a complexidade da realidade e a necessidade pelas diversas ciências de estudar, sem exclusivismo, todos os elementos que participam dessa complexidade. Ao contrário do que foi feito durante o período anterior (século XIX e começo do século XX) não mais se procura "provar" os fenômenos chamados "paranormais" através da acumulação de dados quantitativos. De fato, os pesquisadores tomaram consciência que os protocolos de verificação sistemática tendem a isolar o sujeito da sua dimensão afetiva e do seu contexto cultural que, uma como o outro, aparecem fundamentais para a ocorrência das diversas intuições.

Num primeiro momento alguns cientistas analisaram os muitos relatos surgidos a partir dos acontecimentos de Roswell (1947), criando a especialidade chamada de ufologia, estudo dos Objetos Voadores Não Identificados, OVNIS. Depois foram os antropólogos quem, como foi dito, aplicando ao campo europeu os métodos utilizados em terras alhures, aprofundaram o estudo dos EMC (mediunidade, vidência, escrita automática, etc.) na sua própria sociedade. Sendo que esse novo movimento acadêmico começou a modificar a percepção universitária geral sobre o "irracional" os integrantes das ciências psíquicas a sua vez se lançaram na análise do que, para eles, aparecia na sua clínica como elementos destones com o desenvolver de uma psicanálise "clássica", para dizer assim. Na atualidade, alguns pesquisadores estão tentando criar uma síntese de todas essas análises diversas se utilizando de conceitos novos que, construídos através de uma abordagem nova, permitem tomar conta dos diferentes níveis da realidade estudada.

\section{Uma socio-antropologia das paraciências}


Religare, ISSN: 19826605, v.14, n.1, agosto de 2017, p. 60-89.

O conceito de "paraciências", que o trabalho do sociólogo Gerard Chevalier ${ }^{19}$ deixa entrever, é uma dessas tentativas de definir os fenômenos insólitos e as instituições que lidam com eles. Chevalier enxerga as paraciências como saberes e práticas que tentam gravar sobre um conteúdo tradicionalmente religioso, uma forma técnico-científica. A noção de paraciência aglutinaria, desta forma, saberes e instituições com histórias distintas, porém com visões de mundo associadas ao ocultismo, além da ideia de estarem uma mesma condição social de marginalidade nas sociedades industrializadas e principalmente rejeitadas pelas "ciências oficiais" -embora reivindiquem o status de ciência ou procurem se legitimar enquanto ciência.

Astrologia, parapsicologia, radiestesia, geobiologia, a noção de paraciência é um terno cômodo para designar um conjunto de práticas e doutrinas rejeitadas por confissões dominantes e pela ciência oficial. Neologismo instável que desejaria fazer esquecer s limites institucionais da prática científica, ela evoca uma zona imprecisa entre saber e crença ${ }^{20}$.

Chevalier sustenta essa definição para as paraciências com quatro colunas cuja a explicação será inevitavelmente reduzida em sua exposição neste parágrafo. Em primeiro lugar, as paraciências mesmo em sua diversidade e fragmentação confluem sua visão de mundo calcada na teoria das correspondências entre os corpos e os astros tal como foi expressa pelo sueco do século XVIII, E. Swedenborg. Juntam-se a essa releitura os resultados dos estudos sobre a fenomenologia das mitologias primitivas - aquilo que Chevalier chama de "funcionamento intelectual" - presentes nas teorizações da parapsicologia, da radiestesia, da geobiologia e da astrologia, nos quais se constata que os

\footnotetext{
19 « Astrologie, parapsychologie, radiesthésie, géobiologie, la notion de para science est un terme commode pour désigner un ensemble composite de pratiques et de doctrines rejetées par les confessions dominantes et la science officielle. Néologisme instable qui voudrait faire oublier les limites institutionnelles de la pratique scientifique, elle évoque une zone imprécise entre savoir et croyance » (tradução nossa) de CHEVALIER, G. Parasciences et procédés de légitimation. Revue française de sociologie, XXVII, 2, p. 205-219, 1986.

${ }^{20}$ CHEVALIER, G. ibid. p. 2015.
} 
Religare, ISSN: 19826605, v.14, n.1, agosto de 2017, p. 60-89.

chamados "processos lógicos" e a visão de mundo são atualizações do ocultismo. Neste sentido, os conceitos das paraciências como "astral", "éter", "energia", "vibrações", "ondas", "radiações", "campo" (bioenergéticos, bioplasmas, bioelétricos), "fluido" formariam com as noções ocultistas tradicionais uma continuidade cuja a função lógica é servir de mediação entre os elementos perceptíveis e imperceptíveis da relação entre o homem e o seu meio ${ }^{21}$.

Mas, como se expressam as paraciências nas sociedades modernas? Como abordar esse conjunto heteróclito de doutrinas rejeitadas e próximas a uma visão de mundo ocultista? G. Chevalier opta por realizar um recorte para lidar com as paraciências e sua existência social através do que chama de "os modos de comercialização" em que se constituem os signos sob os quais se relacionam o público, a clientela e os profissionais. $\mathrm{O}$ mercado das paraciências se materializa nos salões, nos eventos, nas revistas especializadas, nas escolas e estágios de formação, nas prestações de serviços como as consultas e as terapias. A respeito disso, de acordo com os cientistas sociais D. Boy e G. Michelat ${ }^{22}$ as pessoas na França dos anos $1980^{23}$ geralmente receptivas às ideias paranormais tinham o perfil sociocultural sobretudo ligado à classe média, eram letradas e, com uma significativa índice de frequência, ligadas aos serviços médico-sociais e a quadros da administração pública. Este quadro está dentro do que S. Boy e D. Michelat identificam como a "nova pequena burguesia" -que muitas vezes se declara como "sem religião"- e fazem do interesse pelo paranormal, "uma relação de coexistência e de complementaridade entre as ideias de religiosidade secular trazidas pelas 'ciências' e as crenças religiosas habituais, mas desinteressadas do catolicismo institucional" ${ }^{24}$. Segundo o sociólogo Albert Piette ${ }^{25}$ algumas motivações comuns estariam por trás do interesse das pessoas pelo paranormal, como a curiosidade intelectual após a leitura de livros, audição em conferências;

\footnotetext{
${ }^{21}$ Chevalier. Ibid, p. 206

22 BOY, D. e MICHELAT, G. Croyance aux parasciences: dimensions sociales et culturelles. Revue Française de sociologie, XXVII, 1986, p.175-204.

${ }^{23}$ Lugar e década em que foi feita a pesquisa de D. Boy e G. Michat.

${ }^{24}$ PIETTE, Albert. Ibid, p.97.

${ }^{25}$ Ibid., 1993.
} 
Religare, ISSN: 19826605, v.14, n.1, agosto de 2017, p. 60-89.

ou uma experiência emocional forte como uma NDE, crise de identidade, problemas conjugais e o desejo de resolver essas interrogações existenciais através de uma démarche espiritual; ou até mesmo a procura por serviços específicos numa relação cliente-consumidor.

G. Chevalier, após a análise de um corpus de 19 revistas especializadas dos mais diversos segmentos das paraciências e ao questionar os procedimentos promocionais e das formas de transmissão do conhecimento das paraciências, se depara com o que entende ser um corte entre conhecimento e reconhecimento cultural, causa primordial dos erros recorrentes destas paraciências. É esta diferença entre as aspirações e as competências legitimas que fazem da pesquisa do autor uma análise sobre os sentidos dos signos e das modalidades de recepção dos discursos e práticas para o público. Se trata de compreender o conteúdo das revistas em função das representações e da postura legitimada dos produtores de discurso das paraciências e de buscar as incoerências entre os diferentes planos.

As representações de competência e de postura legitima não podem ser compreendidas indepententemente de um acordo sobre o sentido dos signos, igualmente no erro, entre os produtores das paraciências, seus leitores ou seus clientes ${ }^{26}$.

Em síntese, as paraciências consistiriam em crenças que reatualizam uma visão de mundo ocultista, produzindo por intermédio de suas atividades uma imitação do modus operandi científico, onde residiriam os processos de legitimação. Incluindo a mimetização do modelo escolar e universitário visando, com isso, provocar efeitos de veracidade que perpassa igualmente pelos múltiplos empréstimos tomados às disciplinas científicas como os diplomas dos conferencistas, os prêmios, medalhas e aparições na mídia assim como a sua organização em termos análogos às instituições escolares e científicas com nomes como a "Escola Superior de Astrologia" e a "Faculdade de Parapsicologia". Tudo

${ }^{26}$ Chevalier, G. Ibid., p. 207. 
Religare, ISSN: 19826605, v.14, n.1, agosto de 2017, p. 60-89.

isso seria para a sua clientela, evidências da reivindicação de uma legitimidade cultural, muito mais do que critérios definitivos de uma competência científica intrínseca de suas instituições e de seus membros.

G. Chevalier conclui afirmando que fazer uma sociologia das paraciências significa analisar as formas sociais e históricas que adquirem estas crenças e visões de mundo míticas que tem no saber científico um modelo e critério universal de verdade a ser seguido e imitado. Intimamente aliadas, portanto, a uma visão de mundo mítica (ocultista), as paraciências se comportam como formas culturais históricas sujeitas à dominação simbólica do modo de fazer científico, mas ao mesmo tempo oferecem-se como um sistema de signos a serem reinterpretados ao nível da crença, estabelecendo-se inclusive como "concorrentes" do sistema dominante.

Se os parapsicólogos atuam como cientistas, assim como os curadores como médicos e astrólogos como psicanalistas não é somente para tirar benefício da imitação do saber legítimo e do seu exercício, mas também pela meta difusa e necessária para certos grupos sociais de transmutar em profissões organizadas atividades de substituição ${ }^{27}$.

Por outro lado, se diferenciando desse tipo de abordagem uma outra forma de encarar os fenômenos paranormais e os saberes que deles se ocupam parece também ser o ponto central que aglutina a abordagem de alguns autores contemporâneos de Chevalier, porém, muito mais interessados em questionar e compreender as razões e os julgamentos sobre os fenômenos paranormais colocando uma luz sobre a lógica da rejeição constituída a priori que recai sobre os fenômenos paranormais e sobre saberes e pessoas que deles se ocupam.

Podemos determinar três categorias de interesse por parte dos cientistas que se debruçaram sobre essa nebulosa denominada as "paraciências", tal como

\footnotetext{
${ }^{27}$ «Si les parapsychologues jouent aux scientifiques, tout comme les guérisseurs aux médecins et les astrologues aux psychanalystes, c'est non seulement pour tirer le bénéfice de l'imitation du savoir légitime et de son exercice, mais aussi dans le but diffus et nécessaire pour certains groupes sociaux de transmuer progressivement en professions organisées des activités de substitution ». Chevalier, G. Ibid.,p. 219. (tradução nossa)
} 
Religare, ISSN: 19826605, v.14, n.1, agosto de 2017, p. 60-89.

as definiu G. Chevalier: 1) os que trabalharam com a ufologia; 2) os que se interessaram pelos fatos de vidência ou mediunidade; 3) os que trabalharam com os diversos tratamentos e terapias que fogem ou até se opõem à biomedicina.

\section{Controvérsias em torno das paraciências}

Outro autor que também discute o conceito de paraciências é o antropólogo Pierre Lagrange, ex-orientando de Bruno Latour, cujo objeto de pesquisa consiste na ufologia. Assim como Latour, Lagrange afirma que o mundo moderno e a hegemonia da ciência se construiu sobre a exclusão de uma alteridade dupla. De um lado, os "primitivos", não-ocidentais, imbuídos de um pensamento mágico. E, de um outro, uma alteridade interna característica de ocidentais "fascinados" pelo domínio do "irracional". Segundo P. Lagrange, estes dois processos, que resultam em uma exclusão moderna do obscurantismo pelo saber científico hegemônico, se tornam um campo de atuação da antropologia simétrica cuja análise das controvérsias em torno das paraciências (lembrando, a parapsicologia, a ufologia, a astrologia e a técnica radiestésica) teria como parâmetro epistemológico as sciences studies tais como são realizadas pela proposta de abordagem de Bruno Latour. A iniciativa de uma análise das controvérsias como método de observação e garantia de quebra da assimetria entre pesquisador e objeto de estudo (o paranormal como fato social) está também presente em outros representantes desse grupo de autores ${ }^{28}$ que objetivam, cada um no seu domínio, quebrar a visão de uma associação lógica entre o domínio do paranormal/crença/ilusão de ciência, característica principal por exemplo de abordagens apresentadas anteriormente. Nunca é demais

\footnotetext{
28 A ideia de controvérsia inspirada em Bruno Latour é ferramenta conceitual usada como recurso metodológico que privilegia a dimensão do conflito para denunciar o fenômeno da rejeição e consequentemente marginalização social dos fenômenos e dos saberes paranormais. Ver a tese de doutorado de Bertrand Meheust, "Somnambulisme et médiumnité: le choc des sciences psychiques. 2 vol., Paris, Seuil, 1998" e o segundo livro do psicólogo Renaud Evrard, "Enquete sur 150 ans de parapsychologie" assim como a tese de doutorado de Pierre Lagrange " une ethnographie de l'Ufologie : la question du partage entre science et croyance. Tese de doutorado, EHESS, $2009 »$.
} 
Religare, ISSN: 19826605, v.14, n.1, agosto de 2017, p. 60-89.

lembrar que a nossa intenção se restringe em apontarmos as diferenças principais em estas aproximações pontuando como se constroem os argumentos centrais em cada autor e em quais evidências se baseiam.

Em um artigo que tem um título sugestivo, "Pourquoi les croyances n'intéressent-elles les anthropologues qu'au-delà de deux cents kilomètres? "29, Pierre Lagrange arrisca a hipótese de que o cerne da rejeição ao paranormal e às paraciências estaria dentro de uma outra rejeição que também define como incapacidade dos antropólogos franceses a estudar crenças próximas ao universo cultural dos próprios antropólogos ${ }^{30}$. Dentre algumas evidências para respaldar a sua hipótese, Lagrange cita o artigo publicado na revista L'Homme, em 2001, por Wiktor Stoczkowski que relata um episódio de uma mesa redonda de etnólogos em um evento, o contraste entre o respeito que estes tiveram durante as falas sobre práticas e crenças de culturas diferentes das dos ocidentais, e a reação de risos dos mesmos quando se tratou de uma descrição de práticas de burgueses parisienses adeptos do espiritismo kardecista ${ }^{31}$. O riso como marcador das diferenças de atitude dos antropólogos franceses diante de crenças longínquas -como a magia dos Azande, o xamanismo dos Achuar- e crenças próximas - como o espiritismo kardecista. Assim, haveria uma sociologia (ou uma epistemologia) para as ciências como a representada por P. Bourdieu ${ }^{32}$ e uma sociologia e uma antropologia das crenças como demonstração de uma clivagem da qual são representantes as approches de Jeanne Favret-Saada e a filosofia de Michel Foucault que representam avanços ao revelar aproximações e fluidez entre ciência e ideologia, embora segundo Pierre Lagrange, não consigam

\footnotetext{
${ }^{29}$ LAGRANGE, Pierre. «Pourquoi les croyances n'intéressent-elles les anthropologues qu'au-delà de deux cents kilomètres? ». Politix, 2012/4, n 100, p. 201-220.

${ }^{30}$ A mesma coisa passou no Brasil em relação com o estudo do kardecismo, religião de classe media. Num país onde os estudos sobre religião são muitos, até os anos $\mathbf{8 0}$ quase não existia estudos sobre espiritismo pelo fato que os ciêntistas sociais pertenciam na sua grande maioria as classses medias. Interrogados sobre esse fato os colegas responderam que isso « mexia com eles » porque varios membros das suas respectivas familias praticavam essa religião, cf. Marion Aubrée, conferência pronunciada em 4/12/2009 no departamento de antropologia da UFPE.

31 STOCZKOWSKI apud LAGRANGE, 2012, p. 205.

${ }^{32}$ BOURDIEU, Pierre. O campo científico. In: ORTIZ, Renato. Pierre Bourdieu: sociologia. São Paulo: Ática, 1983.
} 
Religare, ISSN: 19826605, v.14, n.1, agosto de 2017, p. 60-89.

em suas démarches uma quebra da assimetria e do menosprezo das ciências e em particular das sociais pelas crenças e paraciências. Para realizar uma sociologia ou antropologia simétricas das paraciências, é preciso, segundo o autor, eliminar a distância entre "as ciências" e "as crenças" como se estas últimas fossem sempre resultado de fatores sociais enquanto as primeiras pela sua reflexividade e autonomia estariam imunes. Neste sentido, deveria-se buscar como, nas sociedades, toda uma gama de seres (estrelas, micróbios, partículas, extraterrestres, espíritos) fazem parte do tecido social enquanto uma população plural de não-humanos cuja agência pode ser observada. Então não se trata de mostrar, como no problema da loucura e do nascimento da medicina em $\mathrm{M}$. Foucault, a maneira como as ciências podem flertar e até se formar numa mezcla com as ideologias, mas de ampliar a visão sobre um social enriquecido de associações múltiplas entre humanos e não-humanos e com isso, perceber formas de participar da vida social. Segundo Lagrange, a sociologia e a antropologia enquanto disciplinas não podem mais manter seu discurso crítico e assimétrico sobre as paraciências enquanto simplesmente crenças, reduzindo-as em modelos que discutem apenas as influências de fatores sociais marcadas pelo irracionalismo e sobretudo o erro. A sociologia e a antropologia das paraciências, analisando-as em suas diferenças, seriam úteis para abrir perspectivas novas sobre a pluralidade dos mundos e de realidades construidas e não simplesmente sobre a pluralidade das percepções -como o caso do que se opera ao ficar engessado na noção de crença.

Não seria melhor substituir o menosprezo colocado sobre as crenças por uma verdadeira descrição da maneira de produzir o social em misturando não somente seres 'naturais', mas seres "sobrenaturais" ou "parnormais" ?33

\section{Levando a sério a ufologia}

33 (Tradução nossa) Lagrange, P. 2012/4, p. 214. 
Religare, ISSN: 19826605, v.14, n.1, agosto de 2017, p. 60-89.

Desta forma, Lagrange propõe desconsiderar a ufologia como crença em ovnis evitando colocar esta paraciência no domínio das dicotomias comuns como realidade $\mathrm{x}$ não realidade dos fenômenos, a racionalidade $\mathrm{x}$ irracionalidades dos protocolos de pesquisa. Isto significa levar a sério uma etnografia dos afazeres e do conteúdo produzido por ufólogos dando igualmente conta das distinções entre os grupos de amadores e as instituições privadas e outras cujas pesquisas são financiadas pelos órgãos ligados aos estados nacionais. Assim como levar a sério para Lagrange teria que igualmente analisar as mudanças ocorridas ao longo das décadas entre as pesquisas, as sondagens sobre testemunhas, as plataformas de divulgação e porque não as teorias. Lagrange se propõe a descrever a maneira como grupos de ufólogos produzem seus fatos sem colocar a hipótese a priori de que seriam discursos irracionais ou pseudo-científicos. Propondo-se a seguir os complôs e as controvérsias em torno dos discursos da ufologia, Lagrange procura entrever as estratégias dos atores, os argumentos contrários, mostrando muitas vezes que há deslizes e travessias das fronteiras entre os papéis de "céticos" e "adeptos" ${ }^{34}$. P. Lagrange tece a seguinte consideração sobre as controvérsias de que não são os erros de percepção ou as alucinações ou mesmo as crenças que renderiam artificiais o material dos ufólogos

\section{Uma antropologia da vidência}

A problemática da rejeição ao domínio do paranormal pode ser observada também a partir dessa citação do antropólogo, François Laplantine, em seu livro “Un voyant dans la Ville"35.

Esta forma de pensar está tão araigada em nossa cultura que passou a ser para uma maioria de nos a única forma de

\footnotetext{
${ }^{34}$ LAGRANGE, Pierre. Enquêtes sur les soucoupes volantes : la construction d'um fait aux États-Unis (1947) et en France (1951-54). Terrain, Carnets du Patrimoine Ethnologique, no.14, março 1990, p.92112.
}

35 LAPLANTINE, F. (org.). Un voyant dans la ville, Paris, 1985. 
representar nos e de organizar nossas atividades. Julgamos os outros a partir do que eles dizem, não do que eles veem (...). Por todos esses motivos essa rejeição da vidência se assemelha a recusa do estrangeiro cuja diferença paree insuportavel porque ele faz perigar nossa identidade e nossa propria visão do mundo. Mesmo que a acusação de bruxaria não quafifica mais essa atitivada (apesar de ser considerada como ilegal) os científicos tendem sempre a lhe dar um lugar de excentricidade social ou de patologia mental, cuando não ambos. Por outra parte, a época, que registra uma mania antiracionalista inédita, tem todo para confirmar seus sabios naquela atitude. ${ }^{36}$

Aqui como na abordagem de P. Lagrange, o que se coloca como potencialmente heurístico é a própria denúncia de um modo de pensar, ou melhor, de um discurso "enraizado" na cultura francesa - e que nesse caso faria até mesmo parte da identidade nacional- que se constitui na rejeição ao tema da vidência. Tendo como um dos protagonistas a imagem do "cientista" que relega ao domínio da irracionalidade e excentricidade tais fenômenos que não devem ser levados, portanto, a sério, se reserva o lugar na sociedade para uma alteridade que provoca no intelectual o menosprezo.

Em páginas mais adiante de seu livro, François Laplantine assinala como uma atitude particularmente francesa essa de uma désaffection em relação à vidência e aos fenômenos paranormais - e de quebra a algumas instituições que deles estudam- e que se torna expressamente visível após a segunda guerra mundial.

A disponibilidade à adivinhação e mesmo a possessão é rigorosamente universal. Mas o que distingue radicalmente nossa sociedade de todas as outras é que ela é -depois de muitos séculos- o lugar de uma supressão (um recalque) histórico massivo e de um refutar sistemático provocando por reação um movimento de entusiasmo também incondicional ${ }^{37}$.

F. Laplantine acrescenta inclusive que essa rejeição cultural e sobretudo acadêmica contrasta inclusive com a recente flexibilização e mesmo aceitação de pesquisas sobre estes temas em órgãos públicos como ministérios, universidades

\footnotetext{
36 Laplantine, F. 1988, p. 12, 13. (As evidências em itálico na citação são ênfases de nossa parte).

37 Laplantine, F. Ibid. p.21
} 
Religare, ISSN: 19826605, v.14, n.1, agosto de 2017, p. 60-89.

em outros países de industrialização avançada como é o caso dos Estados Unidos, Grã-Bretanha e Alemanha. François Laplantine propõe, com isso, que as ciências sociais possam se interrogar sobre as razões dessa rejeição cultural do "irracional" e que teriam como uma das consequências a marginalização e o descrédito no meio científico apesar do tema estar largamente presente na literatura, na mídia e, portanto, na opinião pública.

Os institutos e fundações conhecidas como psychic research e na França métapsychique no final do século XIX como os já citados, Institut de Metapsychique International (IMI) em Paris e a Society for Psychical Research (SPR), representam o embrião daquilo que será conhecido (após sobretudo a abordagem do psicólogo americano, Joseph Banks Rhine e de Max Dressoir) como parapsicologia, cujo objeto de estudo são os chamados "fenômenos psi", isto é, a telecinese e as experiências extra-sensoriais. $\mathrm{O}$ antropólogo francês assinala mesmo que o nascimento da parapsicologia representa uma ruptura com a tradicional interpretação mágico-religiosa que imperava sobre os fenômenos paranormais no mundo ocidental, pois representariam a primeira tentativa de colocá-los no laboratório com a intenção de mensurar e examinar sua natureza ${ }^{38}$.

Por que se deveria fazer mais confiança nos cientistas (a maioria) que refutam a vidência do que naqueles que são convencidos da sua existência? Porque (...) tudo na nossa cultura nos predispõe a acreditar nos primeiros ${ }^{39}$.

Ora, para o antropólogo, essa rejeição se daria por razões psicoafetivas e socioculturais que em nada têm a ver com a ciência em si. A comunidade científica teria dificuldade em aceitar no seu seio fatos novos tendo na maior parte do tempo estudos que reproduzem os fatos já conhecidos. E, cita o caso da semelhança da ilegitimidade do status social e acadêmico da hipnose com o da vidência. Em ambas, as mesmas razões para a rejeição estariam ligadas ao

\footnotetext{
${ }^{38}$ Ibid., p. 22 .

${ }^{39}$ Ibid., p.34.
} 
Religare, ISSN: 19826605, v.14, n.1, agosto de 2017, p. 60-89.

contexto em que surgem (final do século XIX onde se misturam religião e jeux de société) e aos seus conteúdos extracomuns. Uma outra razão residiria no fato de que o reconhecimento da veracidade da clarividência e da premonição colocaria em cheque uma das especificidades da cultura francesa ocidental arraigada em um pensamento racional fundamentado em distinções pontuais entre passado, presente e futuro e de causalidade entre estas temporalidades além de questões precisas sobre a subjetividade onde não caberia sem prejuízo distinções entre "um eu e um não-eu".

Essas categorias dualistas, na sua origem não poderiam ser mais culturais, pois nenhuma sociedade elaborou semelhantes, já aqui se tornaram categorias mentais, à tal ponto que aquele que as transgrida é espontaneamente (quer dizer culturalmente) considerado como um doente mental ${ }^{40}$.

Porém o próprio F. Laplantine foi entre os primeiros antropólogos a estudar ditos fenômenos de mediunidade e de vidência na cidade de Lyon, onde mora. Assim, vários antropólogos se debruçaram sobre a história de vida e a trajetória profissional de médiums mais ou menos conhecidos ${ }^{41}$. A partir destes trabalhos etnográficos foram evidenciados alguns traços característicos da trajetória dos sujeitos estudados. Deste modo, os videntes/médiuns aparecem pelo geral como pessoas que, após um longo percurso de dificuldades afetivas e de dúvidas, chegaram a ser curadores de almas e corpos, capazes de trazer um bem-estar aos que recorrem a eles numa troca simbólica na qual parece ser abolida a distinção entre si mesmo e o outro. Por outra parte resulta dos trabalhos mencionados que os que praticam a cura paranormal utilizam, para descrever suas práticas de "magia curativa", um vocabulário decalcado no vocabulário médico mais usual, como uma forma de legitimação (no sentido descrito por Chevalier acima) do seu

\footnotetext{
${ }^{40}$ Ibid., p.37.

${ }^{41}$ Cf. entre outros : F. Laplantine (dir.) : Un voyant dans la ville : étude anthropologique d'un cabinet de consultation d'un voyant contemporain, Paris, Payot, 1985 et G. Charuty: «De la preuve à l'épreuve », (in) Terrain, $n^{\circ} 14,1990$, pp< ; 47-59.
} 
Religare, ISSN: 19826605, v.14, n.1, agosto de 2017, p. 60-89.

oficio numa sociedade que, apesar de recorrer a eles, continua a marginalizá-los. Por fim, essas etnografias enfatizam o fato de que a maioria destas pessoas se refere aos universos simbólicos cristão ou espirita, o mesmo que os seus "pacientes" aparecem como simpatizantes de uma ou outra dessas duas religiões.

Esses estudos se concentraram sobre o elemento do "invisível" que provoca um interesse mais geral na sociedade francesa e atrai pessoas por curiosidade ou necessidade. Trata-se da vidência que permite ao médium fazer enunciados de retrocognição (ligados ao passado) ou de precognição e premonição (relativos a um futuro). Porém, na França como no Brasil, existem também médiuns que "curam" ou, como foi dito anteriormente, procuram um bem-estar moral ou psicológico aos seus pacientes ${ }^{42}$; existem também médiuns que psicografam mensagens susceptíveis de consolar as pessoas que perderam um ente querido e outros que pintam em forma automática ${ }^{43}$. Cada uma dessas categorias interessa a um ou outro antropólogo, mas, ao contrário do que se passa no Brasil, os estudos finalizados são ainda poucos. Muitos médiuns são, na atualidade, os sujeitos de estudos em curso, realizados por alguns poucos neurocientíficos que, além dos trabalhos sobre doenças diversas, se interessam pelos estados de consciência diferentes experimentados por alguns dos seus contemporâneos no seio de sua própria cultura ${ }^{44}$.

\section{As ciências psiquicas e o psiquismo revisitado}

Além disso, existe um certo continuum histórico com o século XIX, na medida em que grande parte dos cientistas que desenvolvem um interesse

\footnotetext{
42 E interessante notar que na França, ao contrario do Brasil, as pessoas raras vezes procuram os mediums para tratar alguma doença física devido ao fato que o sistema de saúde francês é bastante eficiente.

43 Para exemplos desse tipo ver M. Aubrée e F. Laplantine : La Table, le Livre et les Esprits, éd. J.C. Lattès, Paris, 1990, pp. 323-328 ; tradução brasileira pela EDUFAL, Maceió, 2009,.pp. 380-386.

${ }^{44}$ Ver, entre outros, Thomas Rabeyron : «Les expériences exceptionnelles : entre neurosciences et psychanalyse » (in) Recherches en psychanalyse, 2009/2 (n 8), pp. 282-296.
} 
Religare, ISSN: 19826605, v.14, n.1, agosto de 2017, p. 60-89.

específico para ditos fenômenos é especialistas das ciências psíquicas, entre os quais muitos continuam de assimilar a vidência e a mediunidade a uma ou outras modalidades da psicose. Porém, paralelamente ao desenvolvimento das neurociências, alguns pesquisadores (psiquiatras, psicólogos ou psicanalistas) tentaram explicações novas, relativas em particular à telepatia ${ }^{45}$. Na maior parte das vezes foi a sua prática clínica que os levou a se interessarem por certas percepções discordantes expressadas pelos seus pacientes e frente ás quais eles sentiram a "inquietante estranheza" analisada por S. Freud ${ }^{46}$. Assim, E. LabordeNottale utiliza esse termo para expressar diversas experiências pessoais vividas frente a certos pacientes seus. A posterior pesquisa e análise aprofundada que ela publicou ${ }^{47}$ lhe permitiram esboçar uma teoria da vidência fundada nos conhecimentos psicanalíticos.

Primeiro ela nota, a partir da experiência própria e de entrevistas recolhidas, que a sensação anterior ao enunciado da vidência se concretiza em formas diferentes: imagem visual, palavras escutadas (internamente) ou sensação corporal e que ela se apresenta numa forma automática na qual o emissor nem sempre capta imediatamente o sentido do que ele está percebendo e expressando. Assim, qualquer que seja a modalidade, o sujeito experimenta uma forte impressão de exterioridade que tende a favorecer a crença nos espíritos que ditariam mensagens desde um além indeterminado. Por outra parte essa impressão tem duplo sentido na medida em que os terapeutas, também, podem viver uma percepção similar à dos seu(s) paciente(s) ${ }^{48}$.

Em segundo lugar, ela desenvolve a noção de "scopemas", ou seja, essas imagens fugazes mas, contudo, significantes que permitem ao vidente emitir uma frase, cujo sentido será revelado a posteriori. Ao redor desse trabalho

\footnotetext{
${ }^{45}$ Ver D. Si Ahmed : Comment penser le paranormal, éd. L'Harmattan, Paris, 2006 ou M. Montrelay (org) : La portée de l'ombre, Paris, éd. des Crépuscules, 2009.

${ }^{46}$ Cf. : L'inquiétante étrangeté et autres essais, Paris, éd. Folio essais, 1985.

47 Ver dessa autora : La voyance et l'inconscient, éd. du Seuil, Paris, 1990, p. 53.

48 Ver M. de M'Uzan : «Contre-transfert et système paradoxal » (in) Revue française de Psychanalyse, $\mathrm{n}^{\circ} 3$, Paris, PUF, 1976 assim como os varios exemplos vividos e contados por E. Laborde-Nottale na sua obra citada.
} 
Religare, ISSN: 19826605, v.14, n.1, agosto de 2017, p. 60-89.

detalhado, a autora analisa os elementos de interrelação telepática entre emissor e interlocutor que podem incidir sobre a intuição verbalizada e confirma, pela própria experiencia, um lugar comum que circula amplamente segundo o qual "as representações visuais se transmitem melhor" de um ao outro ${ }^{49}$.

A partir dessas análises, Laborde-Nottale infere que são informações fragmentárias percebidas sob várias formas (palavras, formas, sensações) pelo emissor que ficam articuladas num enunciado coerente, fruto da interpretação imediata do vidente. Cada um dos videntes pode ser sensível a demandas particulares do interlocutor (saúde, sofrimento ou morte), outros se interessam por temas amorosos, etc. Podemos dizer assim que, nessa obra, a vidência é analisada como uma interação psíquica forte entre duas personalidades e que, na parte onde analisa o eventual determinismo cultural e psicológico que faz do vidente o que ele é, Laborde-Nottale concorda plenamente com as análises dos antropólogos sobre um percurso afetivo difícil que fomentou no vidente uma predisposição a benevolência e compreensão do outro.

Por outro lado, uma outra aproximação dos fenômenos paranormais é aquela realizada por psicólogos clínicos numa abordagem conhecida por psicologia anomalística que revisa e rediscute os conceitos de alucinação e delírio da psicopatologia em uma perspectiva que o retira da associação imediata com os estudos sobre psicose. Colocando em evidência a noção de experiências excepcionais se pretende empreender uma análise denominada " antropologia clínica das margens" ${ }^{50}$ para discutir o problema da relação terapeuta-paciente no que tange aos afetamentos dos pacientes com relação aos fenômenos paranormais. "Antropologia clínica" se encarnaria na atividade do terapeuta auxiliando-o na escuta das diferenças trazidas pelos pacientes permitindo ao profissional uma despatologização e desmedicalização dos comportamentos trazidos por pacientes que dizem ver espíritos, ouvir vozes, sair do corpo e não

\footnotetext{
49 op. cit., p. 117.

${ }^{50}$ EVRARD, Renaud. Folie et paranormal : vers une clinique des experiences exceptionelles. Rennes : Presses universitaires de Rennes, 2014.
} 
conseguem revela-las por receio de prejulgamentos em uma relação terapêutica ortodoxa. Antropologia clínica no auxílio como ferramenta de questionamento do psicólogo clínico é um dos exemplos de como novas abordagens que rediscutem a questão das diferentes vias de construção histórica da fabricação do psiquismo nas sociedades ocidentais podem, como vamos ver agora, enriquecer ainda mais esse tema controvertido.

\section{Técnicas do espírito e estados alterados de consciência}

Nos deparamos com um outro modo de abordagem e igualmente um desafio para tentar superar a rejeição acadêmica ao domínio do "irracional" nas obras ${ }^{51}$ da antropóloga e historiadora das religiões Silvia Mancini da Universidade de Lausanne na Suíça. Ela aborda o tema dos estados alterados de consciência enquanto faculdades extraordinárias da psique e contextualizados nos inúmeros casos das sociedades onde estão presentes os fenômenos de possessão e processos de curas. Procurando escapar de uma interpretação em que os fenômenos insólitos estejam presos ao debate tradicional sobre a realidade objetiva ou a eficácia factual, Silvia Mancini recorre aos conceitos de "tecnologias de espírito" e "ortopráticas", vistos como psicotécnicas, ferramentas para pensar a dimensão da interação entre estes estados não ordinários de consciência em suas formas históricas, sociais e ideológicas.

O leitor deve estar se interrogando sobre as filiações teóricas desse modo de tratar os ritos mágico-religiosos e os estados alterados de consciência. Não discutiremos todas as influências que se encontram na abordagem de Silvia Mancini, mas pensamos ser interessante destacar questões centrais da antropologia e história das religiões que ela retoma, como é o caso da questão da eficácia simbólica dos ritos dirigida às instituições, às práticas e às representações conhecidas "como mágico-religiosas, como técnicas definidas por um modus

\footnotetext{
${ }^{51}$ MANCINI, Silvia. Savoir-faire techniques et orthographiques rituelles au carrefour des sciences humaines et des sciences de la vie. In : MANCINI, S. (org.) La fabrication du psychisme : pratiques rituelles au carrefour des sciences humaines et des sciences de la vie. Paris: La Découverte, 2006, p.0739.
} 
Religare, ISSN: 19826605, v.14, n.1, agosto de 2017, p. 60-89.

operandi particular" ${ }^{\prime 2}$. Procura se distanciar de abordagens teológicas e filosóficas da religião para abordar o problema do mágico-religioso em se aproximando de uma perspectiva construtivista calcada em pressupostos históricos e empíricos (trabalho de campo). Com isso, se esquiva igualmente de uma interpretação substancialista, cognitivista e hermenêutica do universo mágico-religioso. Em termos diretos, Mancini evita uma hermenêutica e uma perspectiva cognitivista das concepções, práticas e instituições mágico-religiosas se esquivando de uma preponderância da "noção de crença" como "modo de pensamento" o que lhe custaria uma aproximação indesejada com o cognitivismo ou de uma noção de crença como receptáculo de uma "experiência de vida no mundo"53. A ideia central é evitar tratar as práticas mágico-religiosas em que ocorrem os estados alterados de consciência como produtos de um sistema de representações mentais, mas pensá-los como "savoir-faire" aplicados e eficazes onde entram em jogo dispositivos técnicos e específicos, isto é, as ortopráticas. Os mitos e os ritos são encarados como formas e instrumentos de ação com uma eficácia acionada pelo dispositivo particular.

A noção de "tecnologias do espírito" emprestada a C. Bergé54 se encaixa para dar conta de atividades em que há estados de possessão ritual, nas práticas de exorcismo, nos comportamentos ascetas mobilizados em contextos místicos ou iniciáticos, no transe xamânico, nas práticas de meditação, diversas formas de exercícios espirituais que se inscrevem na tradição cristã, mas, também, nos savoir-faire à l'oeuvre nos contextos seculares, tais quais os menémotecnicos na Renascença, destinados à introjeção de sistemas de diversos conhecimentos, podemos ajudar a isto certas modalidades de enquadramento pedagógico seguida em instituições escolares ou militares, ou ainda nas práticas psicoterapêuticas como a hipnose. Em todos esses casos, se encontram invocados os estados psíquicos particulares, como o transe, auto-hipnose, dissociação mais ou menos pronunciados da personalidade, estados oníricos ou oniroïdes ${ }^{55}$.

\footnotetext{
${ }^{52}$ MANCINI, S. 2006, p. 17-18.

${ }^{53}$ MANCINI, S. p. 21

${ }^{54}$ BERGÉ apud MANCINI, ibid., p. 22.

${ }^{55}$ MANCINI, S. p.22
} 
De acordo com Silvia, a história e a antropologia das religiões abordam estes fenômenos sem, contudo, se interessar pelos estados psíquicos em si, como já dito acima, mas se interessando pela sua "função cultural" que exerce a produção institucionalizada (pelos ritos) dos estados alterados de consciência. E exatamente pelo fato destes fenômenos estarem dentro de um quadro institucional, eles respondem ao regime controlado de dissociação psíquica da vida social no qual está inserido. Aliás, a antropologia já rediscutiu exaustivamente a despatologização dos estados alterados de consciência nas sociedades tradicionais há algum tempo. Lembremos de Claude Lévi-Strauss que havia remarcado a partir da obra de M. Mauss a ideia de despatologizar figuras sociais como o xamã. "Vemos bem como e por que um feiticeiro é um elemento de equilíbrio social; a mesma constatação se impõe para as danças ou cerimônias de possessão" ${ }^{56}$.

No entanto, não devemos confundir o leitor e fazê-lo pensar que apesar de pensarem em despatologização dos estados alterados de consciência e da ideia de equilíbrio social, a démarche de Silvia Mancini se aproximaria do estruturalismo de C. Lévi-Strauss. Isso se nota imediatamente na medida em que a autora enfatiza a importância da vontade consciente do agente como catalizador do rito. Na verdade, a antropóloga recupera a ideia de uma "criação psíquica" - presente em certas correntes vitalistas e neovitalistas dos séculos XIX e $X X^{57}$ - para entender o papel da intencionalidade consciente na eficácia factual de certas práticas simbólicas e para construir a hipótese de uma natureza energética e dinâmica do psiquismo humano animado, por sua vez, por um finalismo interno que colocaria em curso processos que por especializações

\footnotetext{
56 « Nous voyons bien comment et pourquoi un sorcier est un élément de l'équilibre social ; la même constatation s'impose pour les danses ou cérémonies à possession » » (tradução nossa) da obra LÉVISTRAUSS, C. Introduction à l'œeuvre de Marcel Mauss. In: MAUSS, 1950: IX : LII.

${ }^{57}$ A ideia de uma força, de vontade e de imaginação ativa, de uma realização plástica da ideia advém de uma interface que Silvia Mancini estabelece com os trabalhos de Bertrand Meheust sobre a importância e contribuições do magnetismo animal e as polêmicas que enseja dentro da Academia de Medicina e posteriormente entre na formação da métapsychique francesa e das ciências psíquicas anglo-saxãs. Ver MEHEUST, B. op. cit.
} 
Religare, ISSN: 19826605, v.14, n.1, agosto de 2017, p. 60-89.

sucessivas (iniciações, por exemplo) desdobraram-se de estados pre-individuais a formas cada vez mais e mais individuadas, complexas e conscientes, com o recurso das atividades mítico-rituais. Estamos vendo a distância para a concepção estruturalista em que o processo cognitivo de simbolização seria resultado stricto de uma operação linguística e semiológica do homem. Os símbolos para Mancini, ao invés de significarem a realidade em um plano puramente metafórico ou convencional das representações, seriam, por sua vez, prolongamentos desta mesma realidade das quais eles mesmos consistem em "a expressão direta -não de fato arbitrária- de camadas inferiores e menos diferenciadas do psiquismo que permitem melhor compreender os fenômenos miméticos e sugestivos reparáveis de certas condutas rituais" 58 . Os fenômenos carregados de expressões simbólicas favorecem a confusão das fronteiras de identidade dos atores do rito e que favorecem, com isso, a operação de uma modificação do sujeito em ritos de possessão, cultos estáticos, práticas iniciáticas, ritos mágicos de (des)encantamento, cerimônias de ritualização do luto. Tal concepção do psiquismo humano e sobre a eficácia simbólica dos ritos mágicos definitivamente não aproxima a approche de Silvia Mancini do estruturalismo lévi-straussiano, porém a coloca como herdeira do historiador das religiões e antropólogo italiano Ernesto De Martino, mais precisamente nas obras em que De Martino discute a questão do magismo em seus trabalhos de campo no sul da Itália durante os anos $1940^{59}$. S. Mancini herda a noção de "des-historisação mítico-ritual" de De Martino que lhe permite compreender como as técnicas mágico-religiosas institucionais consistem em estratégias práticas e instrumentais que permitem ao homem de se proteger, defender, reforçar ao abrigo de contingências e crises imponderáveis da existência, substituindo sua incapacidade momentânea de agir e controlar estes imponderáveis. Nesse sentido, o rito seria compreendido como um dispositivo técnico de "des-

\footnotetext{
${ }^{58}$ MANCINI, S. 2006, p.32.

${ }^{59}$ De Martino, E. Italie du sud et magie. Paris : Sanofi-Synthélabo, coll. «Les Empecheurs de penser en rond », 1999.
} 
Religare, ISSN: 19826605, v.14, n.1, agosto de 2017, p. 60-89.

historização mítico-ritual", um operador eficaz que assegura a correção simultânea da realidade e do sujeito em estados alterados de consciência, facilitando a passagem crítica de um estado de aflição psíquica a outro de saúde ou da condição de possuído ao de senhor de si ou de um regime de identidade a outro. Mancini assinala essa capacidade de organizar um reequilíbrio orgânico, psíquico e cultural das ortopráticas utilizando-se da expressão de De Martino "pedagogia da presença" que expressa pelo rito justamente esse repertório das performances onde se reestabelece a garantia de uma unidade psíquica e existencial do sujeito ${ }^{60}$.

Ao explanar ao leitor a filiação teórica de Silvia Mancini, precisamos mostrar em que essa herança resulta na própria abordagem da historiadora e antropóloga das religiões que em seu próprio olhar sobre os fenômenos ligados aos estados alterados de consciência, propõe dissolver os limites que impediriam a aproximação em um mesmo estudo de fatores psicofisiológicos e históricosociais-culturais. É aqui que a autora lança a ideia de uma realidade psicoorgânica-cultural -a que chama de "biotope cultural"- como base para o estudo interdisciplinar das ortopráticas. Se trata de pensar os "savoir-faire" (saber-fazer) suscetíveis de deslocar os parâmetros dos pares, entre esfera psíquica e ordem fisiológica/física. Assim, como F. Laplantine e P. Lagrange, a autora afirma que a modernidade e a emergência e preponderância do trabalho científico e da técnica - preconizada com o Iluminismo e, em seguida, reforçada pelo positivismo- teria impedido de se pensar para além destes dualismos presentes nas concepções hegemônicas que interpretam as relações entre o homem e a natureza.

Segundo Mancini, colocar em suspensão as amarras de um pensamento racional, com suas excessivas e apriorísticas suspeitas em relação aos estados alterados de consciência e em relação à pesquisa dele em ciências humanas permite assim que se libere um conjunto de questões sobre sua dimensão cultural e histórica. O conceito de cultura é aqui tido como um sistema plástico de

${ }^{60}$ MANCINI, S. 2006, p.28-29. 
emergências, de adaptação e de respostas, capaz de auto-organização, autoreparação tornando possíveis pela contribuição de diversos tipos de regimes psíquicos sendo cada um caracterizado por níveis de individuação suscetíveis de reconfigurar o sistema global. Desses regimes psíquicos a cultura extrai a sua capacidade inesgotável de se reprogramar, de se ajustar/reparar ${ }^{61}$.

Donde brota, e como funciona esse savoir-faire cujos indivíduos e grupos fazem prova, e que lhes permite cultivar intencionalmente a defasagem, a desindividuação, a crise e a separação não intencionais que precisamente visam combater os riscos que incorrem em interações violentas com os eventos? Qual o papel da mimesis, da dramatização e da ficção no processo de exploração cultural de estados dissociados ${ }^{62}$

Essa posição teórico-metodológica visa reconciliar ciências humanas e "ciências da vida" numa démarche alternativa usada para quebrar os dualismos epistemológicos entre espírito/natureza, mundo subjetivo/mundo objetivo encrustadas na racionalidade moderna. A ordem dessa iniciativa é se distanciar tanto das filosofias da consciência (como a hermenêutica) quanto com o scientisme, característica do positivismo vendo ao mesmo tempo a práxis como um lugar de construção do mundo e do sujeito no mundo onde se consideram os processos cognitivos como "ortográficos" -orthographiques- que constroem ao mesmo tempo a ordem do mundo e a ordem do homem.

Não obstante, de acordo com Mancini, estudos interdisciplinares e estudos comparativos dos estados de dissociação psíquica e em seus modi operandi diversificados, acionados socialmente para lidar a relação corpo e psiquismo, dariam oportunidades de se pensar alternativas para ultrapassar o modelo hegemônico de pensamento nas sociedades ocidentais. Silvia propõe, com isso, o estudo da função cultural e das formas institucionalizadas de apelo a esses

\footnotetext{
${ }^{61}$ «D'où jaillit, et comment fonctionne, ce savoir-faire dont font preuve les individus et les groupes, et qui leur permet de cultiver intentionnellement le déphasage, la désindividuation, la crise et la dissociation non intentionnels qui ont justement pour but de contrer les risques que font encourir des interactions violentes avec les événements? Quel rôle jouent la mimesis, la dramatisation et la fiction dans les processus d'exploitation culturelle des états dissociés ?" (tradução nossa), MANCINI, S., 2012.

${ }^{62}$ Ibid., 2012, p.10.
} 
Religare, ISSN: 19826605, v.14, n.1, agosto de 2017, p. 60-89.

estados alterados de consciência por parte dos grupos e indivíduos e, com isso, compreender o tipo de eficácia em jogo. Duas diretrizes centrais caracterizariam a problemática no ramo da história ou da antropologia da religião. De um lado, interrogar a relação entre dissociação psíquica e as lógicas simbólicas presentes em certas práticas culturais com vocação "autopoịética". Em seguida, e consequentemente, entrever a lógica e a eficácia em questão que justificam o recurso e a ocorrência da dissociação psíquica.

A observação das formulas culturais encontradas a propósito desses estados psíquicos alterados permitiria analisar os estigmas e as desconfianças ou ao contrário a relevância e o prestígio segundo as sociedades, a época, e outras variáveis de estudo em questão. Esse modelo de análise também privilegia a observação dos tipos de estratégias culturais empregados pelos grupos para promover, explorar, empregar os estados alterados de consciência, seja por intermédio anímico (transe, meditação, ascese, etc.) ou artificial (como psicoativos, danças, hipnose, etc.). Segundo esta démarche, a dissociação psíquica

é vista em seu aspecto processual com fins de construção, reparação e reconstrução, reprogramação de indivíduos e de instituição, mais facilmente perceptível nas ocorrências de crise, conflito e cura.

\section{Referências}

AUBRÉE, Marion. e LAPLANTINE, François. : La Table, le Livre et les Esprits, éd. JC Lattès, Paris, 1990. Tradução brasileira pela EDUFAL, 2009. BASTIDE, Roger : Le rêve, la transe et la folie, ed. Flammarion, Paris, 1972. BERGIER, J. Pauwels, Louis : Le matin des magiciens, ed. Gallimard, Paris, 1960.

BOY, Daniel. e MICHELAT, Guy: Croyance aux parasciences: dimensions sociales et culturelles. Revue Française de sociologie. XXVII, 1986, p.175-204. BOURDIEU, Pierre. O campo científico. In: ORTIZ, Renato. Pierre Bourdieu: sociologia. São Paulo: Ática, 1983.

BROCH, Henri : Le paranormal, ses documents, ses hommes ses méthodes, ed. du Seuil, Paris, 1989.

CAMURÇA, Marcelo. "Religiosidades científicas hoje: entre o secular e o religioso". (In) 
CRUZ, Eduardo R. da. Teologia e Ciências Naturais: Teologia da Criação. Ciências e Tecnologia em diálogo.

CASTANEDA, Carlos : The teachings of Don Juan, University of California Press, 1968.

CHARUTY, Giordana : “Le retour des métapychistes” (in) L'HOMME, n 158 159, avril/sept. 2001, pp. 353-364

CHEVALIER, Gérard : Parasciences et procédés de légitimation. Revue française de sociologie. XXVII, 2, p. 205-219, 1986.

DE MARTINO, Ernesto. : Italie du Sud et magie, Paris, Sanofi-Synthélabo, coll. "Les Empêcheurs de tourner en rond", 1999.

DODDS, E.R. : Les grecs et l'irrationnel, ed. Flammarion, Paris, 1977,

EVRARD, Renaud. Folie et paranormal: vers une clinique des expériences exceptionelles. Rennes : Presses universitaires de Rennes, 2014.

FAIVRE, Antoine : Accès de l'ésotérisme occidental, ed. Gallimard (2 vol.), Paris, 1996.

FAVRET-SAADA, J . : Les mots, la mort, les sorts - la sorcellerie dans le Bocage, éd. Gallimard, Paris, 1977.

HOSKIN C.H. (alias Lobsang Rampa) : Le troisième oil, ed. Albin Michel, Paris, 1957.

LAGRANGE, Pierre. Pourquoi les croyances n'intéressent-elles les anthropologues qu'au-delà de deux cents kilomètres ? Politix, 2012/4, $\mathrm{n}^{\circ} 100$, p. 201-220.

Enquêtes sur les soucoupes volantes : la construction d'um fait aux États-Unis (1947) et en France (1951-54). Terrain, Carnets du Patrimoine Ethnologique, no.14, março 1990, p.92-112.

LAPLANTINE, François (org.). Un voyant dans la ville. Paris, 1985.

LEIRIS, Michel : La possession et ses aspects théâtraux dhez les Ethiopiens du Gondar, ed. Plon, Paris, 1958.

LEVITT, N.J. : Prometheus bedeviled, Science and the contradictions of contemporary culture, Rutgers Univ. Press, New Brunswick, 1999.

LÉVI-STRAUSS, C. Introduction à l'œuvre de Marcel Mauss. In : MAUSS, 1950 : IX : LII.

MANCINI, Silvia. Savoir-faire techniques et orthographiques rituelles au carrefour des sciences humaines et des sciences de la vie. In : MANCINI, S. (org.) La fabrication du psychisme : pratiques rituelles au carrefour des sciences humaines et des sciences de la vie. Paris : La Découverte, 2006, p.07-39.

MANCINI, S., \& FAIVRE, A. (org.). Des Médiums. Techniques du corps et de l'esprit dans les deux Amériques. Paris : Editions Imago, 2012.

MANCINI, S E MEHEUST, B. : “La réponse des métapsychistes", (in) L'HOMME, n 161, 2001, pp. 225-238.

MÉHEUST, Bertrand. Somnambulisme et médiumnité. Paris : Les Empêcheurs de penser en rond, 1999. 
Religare, ISSN: 19826605, v.14, n.1, agosto de 2017, p. 60-89.

MÉTRAUX, Alfred: Religions et magies indiennes d'Amérique du Sud, ed. Gallimard, Paris, 1967.

MONTRELAY, Michel (org.) : La portée de l'ombre, Paris, éd. des Crépuscules, 2009.

ORTIZ, Renato.Pierre Bourdieu, Sociologia, ed. Atíca, São Paulo, 1983.

PIETTE, Albert. Les religiosités séculières. Paris : PUF, 1993

RABEYRON, Thomas : "Les expériences exceptionnelles : entre neurosciences et psychanalyse", (in) Recherches en psychanalyse, 2009/2, nº 8, pp. 282-296.

SERVIER, Jean : Dictionnaire critique de l'ésotérisme, ed. PUF, Paris, 1998.

SI AHMED, Djohar : Comment penser le paranormal, éd. L'Harmattan, Paris, 2006. 